\title{
IMPLICAÇÕES ÉTICAS DA ADOÇÃO DE SISTEMAS DE MEMÓRIAS PARA A PRÁTICA DE TRADUÇÃO ${ }^{1}$
}

\author{
Érika Nogueira de Andrade Stupiello
}

O desenvolvimento de ferramentas eletrônicas de auxílio à tradução em muito tem transformado o trabalho do tradutor contemporâneo. Traduzir nos dias de hoje envolve, principalmente, estar munido de dicionários eletrônicos, glossários e bancos de dados, e, na maioria das vezes, abrange também dominar o uso de sistemas de memórias de tradução. As memórias de tradução são definidas por Pym et al. (2006: 8) como "programas capazes de gerar bases de dados de segmentos do texto de partida e do texto de chegada de modo a reutilizar os segmentos pareados". ${ }^{2}$ A inovação desses sistemas é oferecida pelos recursos de recuperação e reaproveitamento de traduções já realizadas. O tradutor contaria com um grande auxílio na manutenção da padronização terminológica, podendo resultar em economia de tempo em trabalhos muito extensos e para aqueles desenvolvidos em equipe.

Ao contrário da tradução automática, o desenvolvimento dos primeiros sistemas de memórias de tradução foi, desde o início, visto com entusiasmo por tradutores que, até então, opunham-se à subserviência à máquina. Diversos trabalhos na área, produzidos tanto por estudiosos quanto pelos próprios tradutores-usuários desses programas - entre eles, Pym (2003), Pym et al. (2006), Pérez (2001), Craciunescu et al. (2004) e, no Brasil, Nogueira e Nogueira (2004) - são bastante enfáticos ao afirmarem e ilustrarem o aumento de eficiência que os sistemas de memórias promovem no trabalho de tradução. Alguns chegam, até mesmo, a atestar a imprescindibilidade da adoção e do domínio do uso desses sistemas para o tradutor profissional manter-se no mercado de trabalho.

Por outro lado, pouca atenção parece ser dada às mudanças que o uso desses sistemas promove nas relações entre o tradutor e a tradução realizada, entre o tradutor e demais colegas tradutores e, em última análise, entre o tradutor e o contratante de uma tradução. Este trabalho apresenta uma análise da questão ética que permeia as relações que

\footnotetext{
1 Agradeço à Fapesp pelos recursos da bolsa de doutorado (processo 06/60974-5) que propiciaram o desenvolvimento da pesquisa que originou este trabalho.

${ }^{2}$ Esta e as demais traduções de referências em língua estrangeira foram feitas pela autora.
} 
se constroem quando o tradutor se dispõe a realizar um trabalho parcialmente automatizado por sistemas de memórias de tradução.

\section{A recuperação e a padronização da produção tradutória pelos sistemas de memória}

Consideradas ferramentas eletrônicas de auxílio ao tradutor, as memórias têm sido abordadas na literatura da área como eficientes recursos em trabalhos com textos extensos e com grande número de repetições terminológicas e fraseológicas, como na tradução de textos em meio eletrônico, manuais técnicos, atualizações de traduções de um mesmo material e, em especial, no trabalho de localização.

Segundo Esselink (2000), desde a década de noventa a indústria da localização é o segmento que mais utiliza ferramentas de auxílio à tradução, em especial, sistemas de memórias. Uma vez que a maior parte de projetos de localização exige atualizações constantes de materiais traduzidos, quase sempre em prazos escassos, as memórias constituem uma forma de reaproveitar trabalhos anteriores e possibilitar a normalização do trabalho, especialmente quando executado em grandes equipes de tradutores, uma situação bastante comum nessa indústria.

O formato dos textos produzidos e circulados em meio eletrônico não só possibilitou a introdução e a aplicação de sistemas de memórias de tradução, como também têm contribuído para o aumento do volume de textos a serem traduzidos. Como explicam Biau Gil e Pym (2006: 8), "em alguns setores, o uso de ferramentas de memórias de tradução acelerou o processo tradutório e diminuiu os custos, e isso levou a um aumento na demanda por serviços de tradução". Em setores como o da localização, os sistemas de memórias têm demonstrado o poder de transformar a maneira como o tradutor conduz seu trabalho. Como explicam Biau Gil e Pym,

as memórias de tradução mudam a maneira como os tradutores trabalham. Se um banco de dados de uma memória é fornecido, espera-se que sejam seguidas a terminologia e a fraseologia dos pares segmentados incluídos nesse banco, em vez de se compor um texto com decisões terminológicas e estilo próprios. (2006: 9)

A utilização dos recursos desses sistemas, seja por escolha do tradutor, por critérios impostos pelo cliente ou por ambas as situações, só é eficaz se forem respeitadas as opções terminológicas ou fraseológicas armazenadas na memória, delimitando consideravelmente 
o espaço para as escolhas pessoais do tradutor. A prescrição de normas de utilização das memórias de tradução firma-se na expectativa de que a subserviência do tradutor ao banco de dados, em geral fornecido quando a tradução é contratada, tornaria o trabalho do tradutor sempre melhor elaborado e mais coeso, principalmente em casos de vários tradutores trabalhando em um mesmo projeto.

No artigo "Translation memories: insights and prospects", Heyn apresenta três argumentos que, associados, justificariam a adoção das memórias: o argumento de quantidade, em que textos extensos são traduzidos mais rapidamente; o argumento de qualidade, pelo qual o controle e a padronização terminológica e fraseológica resultam em uma tradução de melhor qualidade; e o argumento de reusabilidade, baseado na possibilidade que os sistemas oferecem de reutilizar trabalhos anteriores de tradução (1998: 124). Conforme explicita, os bancos de dados terminológicos dos sistemas de memórias atuariam como uma espécie de referência autorizada que, por armazenarem opções pareadas previamente revisadas e aprovadas, conduziriam à padronização das traduções.

Embora autores como Heyn afirmem que as memórias não exigem estratégias de língua controlada, como os programas automáticos de tradução - que empregam, em muitos casos, especialistas para elaboração de textos originais de autoria orientada para um devido fim - algumas das táticas empregadas para o controle do uso da língua acabam sendo incorporadas pelo tradutor durante a elaboração da tradução com a finalidade de garantir o reaproveitamento de um trabalho em traduções futuras. Em última instância, a adoção de um modo marcadamente específico de tradução de uma língua pode intervir na qualidade do trabalho final. Essa atitude pode ser exemplificada pela tendência observada, por parte alguns tradutores, de eliminar referências anafóricas e catafóricas para aumentar as probabilidades de reaproveitamento dos segmentos traduzidos, cujo efeito resultante pode ser "um estilo mais técnico e um texto, às vezes, menos legível" (Heyn, 1998: 135).

À primeira vista, a possibilidade de reaproveitamento de traduções anteriores pode ser bastante animadora, tanto para clientes como para os próprios tradutores. Por parte das empresas que necessitam de grandes volumes de tradução, a urgência de redução de custos exerce grande pressão para o emprego dos sistemas de memória, uma vez que se espera que a produção de uma tradução almeje também munir o banco de dados com mais segmentos 
pareados para aproveitamento posterior. Como documenta Murphy, consultora técnica da Berlitz GlobalNET, empresa de consultoria para globalização de páginas da internet,

muitas empresas hoje esperam que os fornecedores de tradução utilizem as ferramentas de memórias para reduzir os custos da tradução. Entretanto, esses mesmos clientes sentem-se com frequência decepcionados quando o nível de reutilização do texto (correspondências $100 \%$ ) relatado pelo fornecedor de traduções é muito mais baixo que o esperado. Por uma análise, geralmente é constatado que a taxa de sucesso inferior está ligada à maneira como o texto de origem é escrito. Na verdade, o texto fonte é reescrito toda vez, portanto, não é uma surpresa que tenha que ser retraduzido toda vez. (2000: 11)

Murphy chama a atenção para a importância de elaboração de construções padronizadas, a fim de evitar que uma ideia recorrente seja expressa de maneiras diferentes em um texto, como nos seguintes exemplos por ela oferecidos:

Center the steering wheel and lock in position.

[Centralize a direção e trave em posição.]

Center the steering wheel. Lock in position.

[Centralize a direção. Trave em posição.]

Center the steering wheel. Lock it in position.

[Centralize a direção. Trave-a em posição.]

Center the steering wheel. Lock the steering wheel in position.

[Centralize a direção. Trave a direção em posição.] (p. 13)

De maneira análoga às práticas limitadoras de uso da língua do texto de origem, observam-se algumas táticas usadas também para os sistemas de memória, em particular para alimentar o banco de dados e aumentar o índice de reaproveitamento das memórias de tradução. Nos trechos exemplificados por Murphy, nota-se que a ocorrência de frases curtas e a substituição do pronome it que age como objeto direto, pelo substantivo steering wheel que, ao ser repetido, elimina a ambiguidade referencial e possibilita a retomada do termo armazenado (ainda que não em uma equivalência total da frase). Observa-se, a partir desse exemplo, que a elaboração textual, em especial a coesão, pode ficar comprometida, muitas vezes, pelo esforço em aumentar o desempenho das memórias, por meio da tentativa de unificação da língua para posterior reciclagem de segmentos de traduções.

Levado às últimas consequências, o uso instrumental da língua como um incremento à produtividade das ferramentas de apoio à tradução, especialmente dos sistemas de memórias, representa um rompimento com o leitor da tradução na medida em 
que prioriza a estrutura e a composição textual do texto de origem, em um esforço para alcançar um paralelismo sintático, muitas vezes estranho à língua da tradução. A atenção do tradutor volta-se ao possível rendimento do sistema de memória com as escolhas que faz para o texto traduzido, perdendo o foco no leitor de sua produção.

Outro efeito do esforço em prol da reutilização de segmentos de traduções anteriores está no tratamento das opções armazenadas de tradução como fixas em detrimento de possíveis mudanças ou atualizações terminológicas que venham a ser necessárias ao longo do tempo. Essa prática também influencia na elaboração textos traduzidos cada vez mais rígidos, que busquem manter a correspondência estrutural com o original a fim de aumentar as chances de reaproveitamento de pares equivalentes em traduções futuras. Os efeitos de uma produção tradutória que tenha em vista não somente a reelaboração textual entre duas línguas para o público leitor da tradução, mas, paralelamente, o aumento da eficácia de aplicação da ferramenta que lhe serve de auxílio em seu trabalho aproximam os sistemas de memória da concepção dos programas de tradução automática, no que tange a regras de controle de produção do texto de origem.

Por ser uma exigência em trabalhos de áreas especializadas, especialmente pela propriedade de promover a coerência terminológica e fraseológica de extensos trabalhos de tradução, a automatização da atividade de tradução, seja de modo parcial pela adoção de sistemas de memórias, ou integral, por meio de programas de tradução automática, sujeita o tradutor a adotar estratégias de uso da língua em conformidade com as restrições técnicas dessas tecnologias, a fim de alcançar o desempenho por elas prometido. Entretanto, como lembra Bowker,

quando se trata de produzir um texto de chegada, os tradutores devem se lembrar que os aspectos de organização textual podem ser específicos de uma língua e cultura. Por exemplo, as línguas podem possuir estratégias diferentes para alcançar a coesão, e o nível global de coesão desejado pode até diferir entre as línguas. Como parte do processo de tradução, os tradutores precisam ajustar os aspectos organizacionais do texto de origem para criar um texto-alvo que atenda às expectativas do modo pelo qual os textos são organizados na língua de chegada. (2006: 177)

A atenção voltada às opções apresentadas pelos sistemas de memórias restringe o trabalho do tradutor com o texto traduzido, podendo prejudicar a expressividade da língua de chegada, especialmente quando o tradutor é orientado para reaproveitar ao máximo os 
segmentos anteriormente traduzidos a fim de atingir o máximo de padronização terminológica e fraseológica em projetos de tradução desenvolvidos por vários tradutores, como será discutido no próximo item.

\section{A divisão do trabalho de tradução promovida pelos sistemas de memórias}

A possibilidade de controle terminológico e padronização de traduções com o uso dos sistemas de memórias proporciona a divisão do trabalho em equipe. Em projetos de tradução, é prática comum o compartilhamento de bancos de dados por tradutores, assim como o reaproveitamento de trabalhos anteriores em novos projetos.

$\mathrm{Na}$ maioria dos casos, os conteúdos das memórias provêm de bancos de dados formados a partir de traduções elaboradas por outros tradutores em outros trabalhos, sendo cada vez mais raras as situações em que o tradutor é integralmente responsável pela pesquisa e adequação terminológicas para a tradução que desenvolve. Biau Gil e Pym oferecem um exemplo de como a comunicação eletrônica possibilita, e até estimula, a distribuição de um trabalho entre vários intermediários:

o cliente pode querer comercializar seu produto em 15 línguas européias. Contratam uma empresa de marketing, que contrata um prestador de serviços linguísticos, que contrata uma série de agentes comerciais para cada língua, que passam o trabalho para uma série de firmas de tradução, que passam os textos para os tradutores, em geral, freelancers. Nesse tipo de sistema, o cliente pode pagar até quatro vezes o que os próprios tradutores estão recebendo por página traduzida. (2006: 7)

Em razão do exíguo tempo com que muitos projetos de tradução contam para serem finalizados e graças à facilidade tecnológica de comunicação e divisão de tarefas, tradutores e outros profissionais envolvidos na produção encarregam-se de etapas distintas da produção desses materiais. Uma das consequências dessa demarcação do trabalho seria o isolamento do tradutor que, por se encontrar, muitas vezes, distante do cliente final e do contexto geral dos textos com que trabalha, acaba limitando sua pesquisa ao banco de dados da memória (ou ao glossário fornecido pelo cliente) e direcionando esforços quase exclusivamente às listas de frases que lhe cabem traduzir, um trabalho que pode isolar e desumanizar a atuação do tradutor.

O cliente que fornece ao tradutor a memória para um trabalho visando a agilizá-lo e reduzir seus custos pode estar criando um precedente para que uma terminologia 
desenvolvida especificamente para um produto a ser lançado seja facilmente acessada por empresas concorrentes. Para evitar quebra de sigilo, é praxe atual clientes celebrarem acordos de confidencialidade com os tradutores contratados. Entretanto, devido à facilidade e à rapidez com que a informação em formato digital pode ser fragmentada e compartilhada, torna-se complexo e, até impossível, impedir sua disseminação.

O risco de vazamento de informações confidenciais pelo conteúdo dos bancos de memórias de tradução constitui uma realidade na indústria de localização, que demanda o emprego de sistemas de memórias por seus tradutores. Em projetos de lançamentos de novos produtos tecnológicos, grandes investimentos são feitos para o desenvolvimento e a padronização de terminologia multilíngue a ser utilizada como fonte de pesquisa para os projetos de tradução correspondentes. Como explica Esselink (2000: 477), a tradução da documentação especializada que acompanha esses produtos tem início, na maioria das vezes, ainda na fase de desenvolvimento do produto, a fim de possibilitar o lançamento e, de preferência, a expedição simultânea (referida em inglês como simship) de uma nova tecnologia, ou um novo software, em diferentes línguas e para diversos destinos. Diante dessa configuração de trabalho, tradutores atuantes no projeto de localização de um produto a ser lançado têm acesso a dados terminológicos ainda desconhecidos pelo público.

A proteção da confidencialidade desses dados é a principal argumentação dos clientes e das agências de serviços de localização e tradução contra o intercâmbio de memórias entre tradutores. Visando a proteger as informações que recebem para o desenvolvimento dos trabalhos envolvidos na localização de um produto, é prática comum das agências limitar o acesso dos tradutores contratados ao banco de dados. A maioria permite que os tradutores conheçam somente as unidades de tradução que utilizarão. Grande parte das agências também adota critérios para a divisão de trabalhos, incluindo a contratação de gerentes de projetos de tradução e a segmentação do material de origem entre vários tradutores, para controlar a produção de seus prestadores de serviços e restringir o domínio desses profissionais sobre o projeto como um todo.

O receio da divulgação de informações técnicas de um produto durante a execução de um projeto tradução faz também com que as agências estabeleçam medidas para coibir a prática de intercâmbio de bancos de dados entre tradutores. Uma das ações tomadas para proteger segredo do conteúdo de materiais disponibilizados para tradução é a celebração de 
contratos de sigilo (conhecidos pela sigla NDAs, em inglês, non-disclosure agreements), entre o contratante de um projeto de tradução e a agência contratada. Nesses casos, a agência torna-se responsável por garantir que seus prestadores de serviços respeitem e mantenham a confidencialidade do trabalho. Para garantir a proteção das informações armazenadas em bancos de dados, Topping (2000: 60) recomenda que os contratos de confidencialidade contenham cláusulas que disponham sobre a propriedade do banco de dados, a quem cabe a remuneração sobre sua criação e quais serão as políticas de reutilização.

Tanto contratantes de serviços de tradução quanto as agências que prestam esses serviços são contrários à divulgação total de conteúdos dos bancos de dados dos sistemas de memórias aos tradutores que executam serviços contratados. Aos tradutores caberia usufruir de uma memória, quando fornecida antes de início de um trabalho, somente para a execução da tradução, e disponibilizar as unidades de tradução resultantes de seu trabalho quando o mesmo é entregue. As memórias transmitidas pelos tradutores contratados são acrescidas ao banco de dados das agências, ou do cliente, que passarão a deter a propriedade de seus conteúdos e a estipular a remuneração por suas reocorrências em trabalhos futuros.

De um ângulo oposto, tradutores autônomos defendem e praticam o intercâmbio de dados entre colegas de profissão, conforme pesquisa realizada por Topping (2000) com integrantes de grupos de discussão via $e$-mail. Como defendem os tradutores pesquisados, o compartilhamento de unidades de tradução seria uma maneira de incrementar o volume de segmentos armazenados nas memórias de tradutores autônomos e as chances de ganho de tempo nos serviços prestados pelo aproveitamente de traduções já realizadas por outros tradutores.

Essa é uma das estratégias de que muitos profissionais têm se valido para adquirir competitividade em relação às extensas memórias mantidas e continuamente expandidas pelas agências de tradução e localização. Questões como a confidencialidade dos trabalhos que realizam não parecem restringir essa prática, pois muitos tradutores argumentam que a descontextualização das unidades de tradução compartilhadas os isentaria do compromisso de sigilo com os clientes, uma vez que, como defendem, não seria possível exportar um texto coerente a partir de um banco de dados de um sistema de memórias (Topping, 2000). 
Quando questionados sobre o fornecimento de seus dados terminológicos ao contratante de um trabalho sem remuneração específica, muitos tradutores tornam-se reticentes. Em um levantamento de declarações de tradutores no fórum de discussão Translator's Café $e^{3}$ em face da questão "Você fornece [ao cliente] a memória de tradução com trabalhos?", muitos informam que só o fazem quando solicitado pelo contratante, especialmente se houver possibilidade de conseguir novos trabalhos. A maioria dos participantes do fórum declara que, por serem deles os esforços para construção da memória, deles também seriam os direitos sobre esta. Com relação a essa prática, Wallis comenta:

é interessante observar, entretanto, que embora os tradutores possam relutar em ceder suas memórias de tradução a seus clientes, alguns estão permutando esses bancos de dados com outros tradutores. Esse fato levanta a questão se esse tipo de intercâmbio é apropriado devido à confusão atual em relação à propriedade dos bancos de dados. (2006: 19, grifo meu)

Wallis trata a questão do direito de propriedade (em inglês, ownership) dos bancos, como um direito legal de posse de um bem tangível e passível de ser comercializado. Bowker caracteriza a discussão sobre a propriedade dos bancos terminológicos como sendo uma "questão espinhosa originada com o advento das memórias de tradução" e afirma que "devido ao fato de as memórias de tradução poderem ser um recurso valioso, tanto tradutores como clientes estão naturalmente ansiosos para reivindicar propriedade" (2002: 122). Julgada por muitos clientes uma extensão natural do trabalho contratado de tradução, a memória é considerada um direito adquirido em conjunto com trabalho. Para Pym, os debates acerca da propriedade das memórias constituem "questões éticas que escapam aos parâmetros de contratos de direitos autorais tradicionais" (2006: 10).

As declarações desses teóricos assinalam a crescente importância que os bancos de dados terminológicos formados com o uso dos sistemas de memórias vêm assumindo na prática tradutória. Elas marcam também o possível início de uma discussão para a qual não foram ainda previstas disposições legais que definam o controle sobre o resultado derivado

\footnotetext{
${ }^{3}$ Os diferentes pontos de vista dos tradutores que integram a lista de discussão do site Translator's Café podem ser lidos na íntegra em <http://www.translatorscafe.com/cafe/MegaBBS/threadview .asp?threadid=4881\&start=61>. Acesso em: 23 maio 2009 .
} 
de uma produção intelectual que, embora seja fornecida como um trabalho à parte daquele contratado de tradução, não está sendo remunerada.

O intercâmbio de bancos de dados entre clientes e tradutores, clientes e agências de tradução e agências e tradutores contratados constitui uma ação rotineira que pode gerar ramificações legais e éticas. A legalidade dessa prática pode vir à tona na medida em que dilui os direitos tanto do contratante, que fornece dados terminológicos ao tradutor para a execução de um serviço, como do tradutor, que repassa ao cliente seu trabalho para compor o banco de dados deste e servir como fonte de consulta e reaproveitamento em futuras traduções que ele venha a contratar.

\section{Considerações finais}

A aplicação de sistemas de memórias de tradução em projetos desenvolvidos em equipe pode estar ocasionando a dispersão da responsabilidade tradutória na contemporaneidade. Seja integrando uma equipe de trabalho para a indústria de localização ou prestando serviços como freelancer, o tradutor teria seu papel limitado à aplicação eficaz de ferramentas tecnológicas para produzir os resultados esperados para um determinado trabalho. Seus conhecimentos linguísticos e a especialidade em uma determinada área do conhecimento podem ser colocados em segundo plano se entrarem em conflito, por exemplo, com uma determinada opção anterior de tradução organizada na memória, à espera de se fazer valer em uma nova tradução.

A automação parcial da tradução com o uso de sistemas de memórias é atualmente responsável pelo encobrimento do trabalho do tradutor, que é instruído (e compelido) a reutilizar traduções anteriores armazenadas na memória. A concepção de tradução como uma operação de recuperação de sentidos estáveis e passíveis de serem controlados retoma ideias caras ao pensamento tradicional que por muito tempo caracterizou o ofício. Em última análise, essa visão do trabalho do tradutor desconsidera seu papel ativo e decisivo na produção de uma tradução.

\section{Referências bibliográficas}

BIAU GIL, José Ramón \& PYM, Anthony (2006) "Technology and translation (a pedagogical overview)". A. Pym et al. (orgs.) Translation technology and its 
teaching. Tarragona, Espanha, 2006. Disponível em http://isg.urv.es/publicity/isg/publications/technology_2006/index.htm>. Acesso em: 22 jun. 2006.

BOWKER, Lynne (2002) Computer-aided translation: a practical introduction. Ottawa: Ottawa University Press,. (2006) "Translation memory and "text". (org.) Lexicography, terminology and translation: text-based studies in honour of Ingrid Meyer. Ottawa: University of Ottawa Press.

CRACIUNESCU, Olivia et al. (2006) "Machine translation and computer-assisted translation: a new way of translating?" Translation Journal 8 (3), jul. 2004. Disponível em: <http://www.accurapid.com/journal>. Acesso em: 15 mai. 2006.

ESSELINK, Bert (2000) A practical guide to localization. Amsterdam: John Benjamins.

HEYN, Mathias (1998) "Translation memories: insights and prospects". L. BOWER et al. (orgs.) Unity in diversity? Current trends in translation studies. Manchester: St. Jerome Publishing.

MURPHY, Dawn (2000) "Keeping translation technology under control". Machine Translation Review 11, Dec., 11-13.

NOGUEIRA, Danilo \& NOGUEIRA, Vera Maria Conti (2004) "Por que usar programas de apoio à tradução?". Marco Rocha et al. (orgs.). Cadernos de Tradução 2 (14), 1735.

PÉREZ, Celia Rico (2001) "From novelty to ubiquity: computers and translation at the close of the industrial age". Translation Journal 5 (1). Disponível em: <http://www.accurapid.com/journal >. Acesso em: 14 mar. 2006.

PYM, Anthony (2003) "What localization models can learn from translation theory". The LISA Newsletter: Globalization Insider 12 (2.4). Disponível em: $<$ http://www.lisa.org/archive_domain/newsletters/2003/2.4/pym.html>. Acesso em: 20 jan. 2007.

TOPPING, Suzanne (2000) "Sharing translation database information: considerations for developing an ethical and viable exchange of data". Multilingual Computing and Technology 5 (11), 59-61.

WALLIS, Julian (2006) Interactive translation vs pre-translation in the context of translation memory systems: investigating the effects of translation method on productivity, quality and translator satisfaction. Dissertação (Mestrado em Estudos da Tradução) - Faculdade de Tradução e Interpretação, Universidade de Ottawa, Ottawa, Canadá. 